\title{
O SERVIÇO DE OUVIDORIA ATRAVÉS DA PESQUISA DE SATISFAÇÃO E LEALDADE DO CLIENTE
}

\author{
Thamirys Nunes dos Santos ${ }^{1}$
}

\begin{abstract}
Resumo
O objetivo deste artigo é apresentar o Serviço de Ouvidoria da SCMM (Santa Casa de Misericórdia de Maceió) como uma área que inclui o instrumento de pesquisa de satisfação e pesquisa de lealdade do cliente aos serviços ofertados pela SCMM. A Ouvidoria da SCMM é um canal de comunicação entre o cliente e a Instituição que propõe ações somadas à atividade essencial de escuta dos clientes/pacientes e usuários dos serviços oferecidos pela Santa Casa de Misericórdia de Maceió. Por meio da pesquisa de satisfação pudemos diagnosticar os gargalos e promover melhorias necessárias, abrangendo aspectos institucionais e de prestação de serviços setoriais. Destacamos como resultado fidedigno da pesquisa a definição da quantidade de clientes abordados, o nível de confiança e a margem de erro. Foi aplicada como metodologia a escala de Likert e o NPS (Net Promoter Score), utilizados para avaliar serviços e identificar o nível de satisfação e lealdade de acordo com o serviço que foi ofertado, sejam pacientes ambulatoriais ou pacientes internos. Neste artigo iremos apresentar o resultado da pesquisa feita no período de março a maio de 2018 dos clientes/pacientes da SCMM. Pudemos identificar que o índice de satisfação e NPS dos clientes pesquisados refletem a experiência deles no hospital e, assim, sugerimos ações de melhorias, com a finalidade de promover maior satisfação aos clientes do Complexo Santa Casa de Maceió.
\end{abstract}

Palavras-chave: Ouvidoria. Pesquisa. Satisfação. Escala de Likert. NPS.

DOI:10.37814/2594-5068.2019v2.p159-171

1 Supervisora Administrativa do Serviço de Ouvidoria da Santa Casa de Misericórdia de Maceió. Graduada em Comunicação Social com habilitação em Relações Públicas pela UFAL. Pós-graduada em Administração e Gestão de Negócios pela UNIT. (thamirysnunes@hotmail.com) (www.santacasademaceio.com.br) (Ouvidoria@santacasademaceio.com.br) 


\begin{abstract}
The purpose of this article is to present the SCMM (Santa Casa de Misericórdia de Maceió) Ombudsman Service as an area of the research instrument of satisfaction and research of customer loyalty to the services offered by SCMM. The SCMM Ombudsman's Office is a communication channel between the client and the Institution, which proposes actions in addition to the essential activity of listening to clients / patients and users of the services offered by the Santa Casa de Misericórdia de Maceió. Through the satisfaction survey we were able to diagnose the gags and promote necessary improvements, covering institutional aspects and the provision of sectoral services. We emphasize as a reliable result of the research the definition of the number of customers covered, the level of trust and the margin of error. Likert scale and Net Promoter Score (NPS) were used as methodology to evaluate services and identify the level of satisfaction and loyalty according to the service offered outpatients and inpatients. In this article we will present the results from March to May of 2018 of SCMM clients/patients. We were able to identify that the satisfaction index and NPS of the clients surveyed reflect their experience in the hospital, so we could suggest improvement actions in order to promote greater satisfaction to the clients of the Santa Casa de Maceió complex.
\end{abstract}

Keywords: Ombudsman. Search. Satisfaction. Likert scale. NPS. 


\section{INTRODUÇÃO}

Na Santa Casa de Misericórdia de Maceió, o serviço de Ouvidoria foi implantado em 2005 e é interligado à Gerência de Marketing do hospital. Anteriormente, as manifestações dos clientes eram recebidas pelo SAC (Serviço de Atendimento ao Cliente), tendo o telefone como único canal de comunicação entre o cliente e a instituição. Com a implantação do serviço de Ouvidoria, abrimos diversos meios de comunicação com o cliente/paciente: presencial, e-mail, site, urnas de sugestão, visitas in loco e, atualmente, as redes sociais.

As Ouvidorias hospitalares foram implantadas como uma das formas pelas quais os hospitais podiam auscultar os "dizeres" sobre a qualidade de seu atendimento. Constituíam-se, portanto, em modalidades institucionais para verificar suas falhas, as quais indicavam problemas estruturais e de funcionamento (PEREIRA, 2002). Assim, a Ouvidoria em saúde é um instrumento da gestão pública e do controle social para a defesa do direito à saúde e do aperfeiçoamento da qualidade e da eficácia das ações e serviços prestados.

Por meio da Ouvidoria, o consumidor pode fazer elogios, denúncias, reclamações e prestar orientações (ZENONE, 2017). Abrir as portas ao cliente é se dispor a receber quaisquer críticas e a promover melhorias, buscando o foco na satisfação do cliente perante os serviços oferecidos pela Instituição.

A Ouvidoria deve ser um intermediador da organização, ter autonomia para defender os interesses dos clientes, desempenhar um papel incorporado ao processo de fidelização. Na atuação do Ombudsman existe proatividade, já que ele busca as informações importantes com os clientes, passando a servir como fonte de informação e possibilitando à empresa adaptar ou criar novas estratégias mercadológicas adequadas às necessidades do mercado (ZENONE, 2017).

Além das atribuições de escuta dos usuários, o serviço de Ouvidoria da SCMM também realiza pesquisas com os pacientes internos e ambulatoriais. Unimos as manifestações dos clientes e as pesquisas para termos uma compreensão completa dos serviços. O resultado da pesquisa, junto com as manifestações do cliente, é compilado mensalmente e divulgado para a alta direção do hospital.

De acordo com REICHHELD (2011, p. 3), “A única forma de saber se uma empresa está cumprindo sua missão e melhorando a vida das pessoas é mensurar sistematicamente o relacionamento com seus clientes". A Santa Casa de Misericórdia de Maceió utiliza a métrica conhecida como NPS (Net Promoter Score), uma pesquisa objetiva e direta que, com uma pergunta simples: "De 0 a 10, qual a probabilidade de você indicar a empresa ' $X$ ' a um amigo ou colega?", torna possível classificar o cliente e medir seu grau de satisfação, e, ao fazer uma segunda pergunta, entender o motivo da sua nota.

Outra métrica utilizada é a escala de Likert, uma escala em 5 pontos para medição de satisfação com um serviço, variando de discordância total até concordância total. Conforme BELL (2008), as escalas de Likert são dispositivos para desvendar a força do sentimento ou atitude em relação a uma série de afirmações. Para o diagnóstico, quanto mais elevadas as categorias, ou seja, quanto mais próximos de 5 , melhores serão os indicadores.

Com o resultado compilado, administramos os indicadores estratégicos, que são de suma importância para tomada de decisões administrativas e assistências do hospital. Nossa meta de indi- 
cadores é baseada em dados históricos da Instituição ou referências nacionais no ramo hospitalar. Melhorar a experiência do cliente/paciente faz parte do nosso planejamento estratégico institucional para assim atingir um elevado grau de satisfação do cliente. Abordaremos alguns meios que facilitam a participação do cliente, os métodos de pesquisa e como os resultados e indicadores serão mensurados, bem como as contribuições para a Instituição.

Compreendemos que a participação do cliente traz grandes contribuições para o desenvolvimento da empresa e, portanto, todos os colaboradores são treinados para que incentivem os clientes a preencher a pesquisa de satisfação e lealdade após o atendimento ambulatorial ou após

alta de internamento. É importante que o cliente manifeste sua experiência após a finalização do atendimento, pois só assim terá uma visão geral do serviço que lhe foi prestado. Como relata GUMMESSON (2010, p. 32), "Os relacionamentos, as redes e a interação estão no centro dos negócios há muito tempo e são fundamentais para que as empresas possam buscar satisfazer seus clientes e alcançar seus objetivos".

O mercado competitivo exige das organizações reflexões sobre como está a satisfação do seu consumidor. Desse modo, a competitividade tem feito com que a percepção do cliente tenha mudado diariamente, onde inovações, avanços e melhorias acontecem surgindo de novas ideias e conceitos. Conforme KOTLER (1998, p. 30), "Marketing de Relacionamento é a prática da construção de relações satisfatórias em longo prazo com partes-chave - consumidores, fornecedores e distribuidores - para reter sua preferência e negócios em longo prazo".

Por meio dos relatos dos clientes/pacientes e das pesquisas realizadas, pudemos analisar a experiência do cliente ou até mesmo captar do cliente o que realmente importa para ele no serviço que está sendo oferecido. O canal de Ouvidoria deve permanecer em constante processo de atualização e escutar do cliente como foi sua experiência, permitindo uma nova perspectiva para prever futuras reclamações, podendo assim antecipar ações de melhorias.

\section{A SANTA CASA DE MISERICÓRDIA DE MACEIÓ}

A Santa Casa de Misericórdia de Maceió, instituição filantrópica fundada em 7 de setembro de 1851, pelo cônego João Barbosa Cordeiro, tornou-se exemplo no cenário nacional por seus investimentos na segurança e na excelência da assistência ao paciente. A Santa Casa de Maceió conta com uma estrutura hierárquica que visa elaborar e normatizar políticas, protocolos, programas e boas práticas institucionais, para acompanhar as atividades de médicos, colaboradores, estudantes e fornecedores, com o intuito de ofertar para a comunidade local um serviço de qualidade nas questões relacionadas à saúde, primando pela atualização da prática baseada nos conhecimentos científicos vigentes.

Na última década houve um aumento qualitativo em todas as áreas da instituição pela adoção de modernas práticas de gestão e pela conquista da excelência nível 3 da Acreditação pela ONA (Organização Nacional de Acreditação), que preza a qualidade nos serviços e o padrão de excelência, principalmente buscando a segurança do paciente, de acordo com o Manual Brasileiro de Acreditação. O princípio desse nível é a "excelência em gestão". Uma Organização ou Progra- 
ma da Saúde Acreditado com excelência atende aos níveis 1 e 2, além dos requisitos específicos de nível 3. A instituição já deve demonstrar uma cultura organizacional de melhoria contínua com maturidade institucional.

Por meio da Instituição Acreditadora - IQG (Instituto Qualisa de Gestão), as instituições de saúde brasileiras podem acessar padrões internacionais de excelência e inovação com oportunidades únicas de troca de expertise e de benchmarking, em parceria exclusiva com a HSO (Health Standards Organization - antiga Accreditation Canada International). A SCMM conquistou em 2016 o nível internacional (Qmentum Diamante), Selo Diamante, focado na excelência do processo, monitorando os resultados, utilizando as melhores evidências científicas e demonstrando a estrutura de forma sistêmica.

Na Santa Casa de Maceió, encontram-se políticas institucionais: Política de Qualidade e o Plano de Segurança (Segurança do Paciente). Como práticas organizacionais obrigatórias ROPs (Required Organizational Practices), elas são respaldadas em evidência e tratam de áreas de alta prioridade em que são centrais a qualidade e a segurança. As ROPs são classificadas em seis áreas de segurança: cultura de segurança; comunicação; uso de medicamentos; vida profissional; prevenção e controle de infecção; e avaliação do grau de risco.

O complexo Santa Casa de Misericórdia de Maceió tem cinco unidades em Maceió: Santa Casa Matriz; Santa Casa Farol (pediatria e obstetrícia privadas); Santa Casa Poço (unidade ambulatorial SUS); Santa Casa Nossa Senhora da Guia (pediatria e obstetrícia SUS); e Santa Casa Rodrigo Ramalho (oncologia).

\section{SERVIÇO DE OUVIDORIA}

O serviço de Ouvidoria atua de maneira imparcial no pós-atendimento, na mediação de conflitos entre o cliente e a instituição, na função de receber críticas, sugestões, elogios, reclamações, em defesa dos direitos e interesses legítimos do cliente. Esse relacionamento permite que a instituição seja mais assertiva na definição de suas estratégias para os clientes.

Ao ouvir o cliente, o Ouvidor/Ombudsman capta informações cruciais para a estratégia organizacional que envolve todas as áreas da instituição. Porém, não basta apenas ouvir, o cliente espera e deseja um feedback que não se limite a palavras e promessas. O cliente tem que perceber que sua voz foi ouvida e que ações foram realizadas mediante as suas críticas. Dentre as competências da Ouvidoria, estão:

- Receber, examinar e encaminhar às unidades administrativas competentes as demandas dos cidadãos e outras partes interessadas, a respeito da atuação do órgão ou entidade pública.

- Articular-se com as áreas administrativas e técnicas com vistas a garantir a instrução correta, objetiva e ágil das demandas apresentadas pelos cidadãos, bem como a sua conclusão dentro do prazo estabelecido para resposta ao cidadão.

- Manter o cidadão informado sobre o andamento e o resultado de suas demandas. 
- Cobrar respostas das unidades administrativas e técnicas em relação a demandas a elas encaminhadas e levar ao conhecimento do gestor do órgão ou entidade os eventuais descumprimentos.

- Organizar, interpretar, consolidar e arquivar as informações oriundas das demandas recebidas de seus usuários e produzir relatórios com dados gerenciais, indicadores, estatísticas e análises técnicas sobre o desempenho do órgão ou entidade, periodicamente ou quando o gestor julgar oportuno.

- Analisar as necessidades e expectativas dos usuários, colhidas por meio de sugestões, denúncias, elogios e reclamações, relativas às ações e aos serviços de saúde prestados à população, com o objetivo de subsidiar a avaliação das ações e serviços de saúde pelos órgãos competentes.

BAPTISTA (1999) lembra que o sistema de Ouvidoria é por si só estático, fazendo-se necessário que os gestores incentivem a participação, divulgando o sistema, mostrando os benefícios potenciais da participação e fornecendo constantemente feedback aos envolvidos. Independentemente da reclamação ou sugestão, o feedback é essencial para a existência de uma Ouvidoria.

Utilizamos diversos meios para realizar a pesquisa com o cliente/paciente, como formulário de pesquisas nas urnas de sugestão e chamadas telefônicas, nomeadas de busca ativa, pois buscam o cliente e não são demandas espontâneas. A intenção é ouvir o cliente não apenas quando se trata de queixa, mas para saber como foi sua experiência conosco, positiva ou negativa, uma vez que o cliente tende a buscar o serviço de Ouvidoria apenas quando deseja realizar uma reclamação.

Diferentemente das urnas de sugestão e via telefone, em que as pesquisas devem ser transferidas para a plataforma utilizada pela Ouvidoria na SCMM, contamos também com duas soluções digitais, que são os totens e o QR CODE, ferramentas de fácil acesso e mais rápidas pelas quais os dados são encaminhados automaticamente para a nossa plataforma via intranet conhecida como SOV WEB (Sistema de Ouvidoria Web), criada e desenvolvida pela equipe de desenvolvimento de Tecnologia da Informação da SCMM em parceria com o serviço de Ouvidoria.

Saber o que o cliente busca e/ou o que importa ao cliente é possível por meio de pesquisa, com perguntas fechadas ou abertas, mas é sempre importante que o cliente tenha um espaço para colocar suas considerações, caso ache necessário.

\section{METODOLOGIA}

A Ouvidoria da Santa Casa utilizou duas metodologias de pesquisa: a escala de Likert e o NPS (Net Promoter Score). A escala de Likert foi criada em 1932 pelo norte-americano Rensis Likert, conhecido por desenvolver trabalhos de pesquisa como diretor do Instituto de pesquisas sociais.

Por meio da escala de Likert, podemos mensurar e entender atitudes ou comportamentos do cliente. A grande vantagem da escala de Likert é sua facilidade de emprego, pois é fácil para o pesquisado (COSTA, 2011). Apresenta-se uma afirmação autodescritiva e, em seguida, é oferecida como opção de resposta uma escala de pontos com descrições verbais que contemplam extremos.

164 | Revista Científica da Associação Brasileira de Ouvidores/Ombudsman - Ano 2 - nº $2-2019$ 
Dentre as opções de respostas, e de acordo com a escala original de 5 pontos, temos: 1) discordo totalmente; 2) discordo; 3) indiferente (ou neutro); 4) concordo; e 5) concordo totalmente. Com isso, é possível identificar os diferentes níveis de intensidade da opinião a respeito de um determinado assunto.

$\mathrm{Na}$ utilização da escala de Likert na pesquisa de satisfação, os clientes que respondem "concordo totalmente" e "concordo" são classificados como satisfeitos. Tornar o questionário mais fácil para quem vai responder deve ser uma preocupação na criação da pesquisa, a fim de aumentar as taxas de respostas e a qualidade dos resultados.

Na pesquisa de nível de lealdade do cliente aos serviços da SCMM, utilizamos o método Net Promoter Score (NPS). Criado em 2003 por Fred Reichheld, após 69 anos da criação da escala Likert, atualmente é a grande referência mundial na mensuração do grau de lealdade dos consumidores (DUARTE, 2016).

Segundo REICHHELD (2011), o objetivo desse método foi criar uma pergunta simples que pudesse ajudar as empresas a criar relacionamentos duradouros e satisfazer seus clientes. O método também busca entender como o cliente está se sentindo e fazer com que os funcionários se sintam responsáveis pela experiência dele.

O NPS é baseado praticamente em uma pergunta quantitativa, padronizada da seguinte forma: "De 0 a 10, o quanto você recomenda nossa empresa a um amigo?". Esse primeiro momento tem como objetivo promover uma categorização dos clientes em três grupos. REICHHELD (2011, p. 4) ressalta que "cada grupo de clientes apresenta um padrão de comportamento diferente e um conjunto próprio de atitudes, e cada um requer um conjunto específico de medidas da empresa". Então, dependendo de como é classificada a forma de tratamento desse cliente, poderá haver diferenciações. Esses três grupos são descritos pelo autor como:

Promotores: pessoas com notas de 9 a 10, indicando que sua vida melhorou depois do relacionamento com a empresa, geralmente compram mais de uma vez e recomendam a amigos ou colegas, são leais a empresa e oferecem feedback construtivo e sugestões.

Neutros: pessoas com notas de 7 a 8 , compram o que precisam e nada mais, são clientes passivamente satisfeitos, não leais, quase não fazem recomendações e, quando fazem, é com ressalvas e sem entusiasmo. Não podem ser contabilizados como ativo de longo prazo. A meta das empresas para os clientes neutros é melhorar seus serviços/produtos e processos para tentar transformá-los em promotores.

Detratores: pessoas que dão nota inferior ou igual a 6, indicando que sua vida piorou depois do relacionamento com a empresa. É um grupo de indivíduos insatisfeitos, decepcionados, que se sentem consternados pelo tratamento recebido e criticam a empresa a amigos e colegas. (REICHHELD, 2011)

De acordo com as notas do Net Promoter Score é possível classificar as empresas em quatro zonas, que em termos gerais exemplificam a posição ocupada pela empresa em relação à satisfação de clientes. As zonas são: Zona de Excelência - NPS entre 75 e 100; Zona de Qualidade - NPS entre 50 e 74; Zona de Aperfeiçoamento - NPS entre 0 e 49; Zona Crítica - NPS entre -100 e -1. 
O questionário da pesquisa consiste em três perguntas. A primeira de NPS, em que será atribuída uma nota na escala de 0 a 10: "O quanto você recomendaria a Santa Casa de Misericórdia de Maceió para um amigo ou colega?; a segunda, uma pergunta de Likert, que irá avaliar na escala entre muito insatisfeito ( 1 ponto), insatisfeito ( 2 pontos), neutro ( 3 pontos), satisfeito (4 pontos) e muito satisfeito (5 pontos): "Como avalia sua experiência enquanto esteve no local?"; e a terceira pergunta: "Qual o principal motivo que contribuiu para sua avaliação acima?".

Os resultados são inseridos no sistema da Ouvidoria, é feita a tabulação, os gráficos são gerados automaticamente conforme são alimentados no sistema. Esse questionário é aplicado pelo serviço de Ouvidoria, por meio dos nossos canais de pesquisa (urnas de sugestão, chamada telefônica, totem e QR CODE).

A margem de erro é o índice que determina a estimativa máxima de erro dos resultados de uma pesquisa. Não há uma margem de erro ideal, mas o indicado é trabalhar com a menor margem de erro possível. Para as nossas pesquisas, utilizamos a margem de erro de $5 \%$.

Outro índice importante é o intervalo de confiança. O intervalo ou nível de confiança representa a probabilidade de uma pesquisa obter os mesmos resultados, respeitando a margem erro, se outro grupo de pessoas em uma mesma população fosse entrevistado. Assim, em uma pesquisa com 95\% de nível de confiança, por exemplo, se a pesquisa fosse refeita 100 vezes, em 95 ela apresentaria resultados dentro do intervalo da margem de erro.

\section{MATERIAL E MÉTODO}

Inicialmente, buscamos as urnas de sugestões como ferramenta para realização de pesquisas. Atualmente existem 46 urnas distribuídas no Complexo Santa Casa de Maceió, disponibilizando um formulário com a pesquisa de satisfação e lealdade e um espaço aberto para o cliente escrever suas considerações, ou seja, nos relatar sua experiência. Os formulários são coletados semanalmente e transferidos para o sistema SOV WEB pela equipe de Ouvidoria, o qual tabula e analisa as percepções dos clientes/pacientes em relação aos serviços fornecidos pela Santa Casa de Misericórdia de Maceió, então os resultados são analisados pelo Ouvidor e é gerado um relatório para as gerências, superintendências, gestores e direção do hospital.

Além das urnas, realizamos ligações telefônicas aos clientes/pacientes que estiveram internados no hospital. A média mensal de pacientes atendidos é de 41.345 e, com base nessa população, foi feito o cálculo amostral com margem de erro de $5 \%$ e nível de confiança de $95 \%$, sendo portanto de 381 clientes pesquisados por mês o mínimo necessário de amostra. No período de março a maio de 2018 foram realizadas 4.214 pesquisas.

Outro método de pesquisa, além do formulário nas urnas e por meio de ligações telefônicas, é o questionário disponível em totem e por QR CODE. Os resultados disponíveis nos totens são integrados com o sistema da Ouvidoria, possibilitando assim a unificação das informações entre formulários de pesquisas, ligações telefônicas, totem e QR CODE. É importante a integração dos dados, para que não se tenham resultados diferentes em cada meio de pesquisa.

Já em 2017, iniciamos com a solução em QR CODE, com o objetivo de atingir um maior número 
de clientes pesquisados. Tendo em vista que a maioria da população tem smartphone e acesso à internet e o hospital disponibiliza a via Wi-Fi, o cliente tem acesso fácil à pesquisa. A solução em QR CODE permite que o cliente nos conte como foi sua experiência sem precisar baixar aplicativo, o cliente/ paciente ao posicionar a câmera no QR CODE é direcionado a uma página da internet contendo a pesquisa. A pesquisa através dessa ferramenta é destinada ao paciente interno, com perguntas direcionadas ao internamento para avaliar, por exemplo, o setor de internação, médico, equipe de enfermagem, nutrição e maqueiro. De acordo com a nota do cliente, existem algumas variáveis nas perguntas que auxiliam para melhor compreensão caso a nota seja abaixo de 3, conforme a escala de Likert.

Todos os meios de pesquisa realizadas na Santa Casa seguem as perguntas de Likert e NPS. Vale ressaltar que alguns canais de coleta podem apresentar desvantagens. Quanto mais se utilizar tecnologia e menos contato humano durante a pesquisa, mais próximos da realidade serão os resultados. Questionários feitos via e-mail, sites ou soluções digitais são alguns dos formatos sugeridos, propondo menor contato humano para evitar a persuasão/influência na resposta.

\section{RESULTADOS E INDICADORES}

Os resultados das pesquisas de satisfação e lealdade nos possibilitaram uma leitura rápida da visão dos clientes para os serviços ofertados. Os resultados podem ser analisados de uma visão geral (todos os serviços do hospital) ou por serviços setoriais. Assim, facilitam identificar os problemas e definir estratégias de melhoria, como também possibilitam perceber o que os clientes gostam em determinado serviço.

Os resultados geram indicadores mensais: o indicador de satisfação do cliente e o indicador de lealdade do cliente ao serviço que Ihe foi ofertado (internamento, emergência ou ambulatorial). Utilizamos esses indicadores como base nas reuniões estratégicas para alta direção, os quais são complementados com outros dados extraídos das manifestações dos clientes. A meta estipulada é de $90 \%$ de clientes/pacientes satisfeitos e nota 80 de NPS, classificada como zona de excelência.

A seguir, apresentamos os gráficos de satisfação e lealdade do cliente e a Tabela 1 apresentando o principal motivo que contribuiu para a avaliação - a pergunta complementar ajuda a entender a nota e os pontos fortes e fracos do serviço.

Os resultados dos Gráficos 1 e 2 apresentados são das pesquisas realizadas com os clientes/ pacientes do Complexo Santa Casa de Maceió, no período de março a maio de 2018. Percebe-se no Gráfico 1, na pesquisa de NPS, o índice de $64 \%$ de clientes promotores, em contrapartida ao índice de $21 \%$ dos clientes detratores. Os clientes passivos correspondem ao índice de $15 \%$. A partir desses resultados podemos calcular a nota NPS. O percentual de promotores menos o percentual de detratores, ou seja, NPS: 64 - $21=43$. No Gráfico 2, o resultado mostra o percentual de clientes satisfeitos com sua experiência no hospital. Considerando os dados abaixo, podemos concluir que $66 \%$ dos clientes se encontram satisfeitos, seguido do índice de $9 \%$ de clientes neutros e do índice de $25 \%$ de clientes insatisfeitos.

De acordo com as zonas de classificação do NPS, o resultado revela que os serviços ofertados pela instituição estão classificados na zona de aperfeiçoamento, ou seja, são necessárias ações de 
melhoria, com a finalidade de melhorar a experiência do cliente no hospital e, consequentemente, sua satisfação. Para que o serviço de Ouvidoria possa sugerir as melhorias, compilamos os principais motivos que contribuíram para a avaliação do cliente, bem como analisamos as manifestações (reclamações e sugestões) recebidas no período da pesquisa para identificar a causa raiz.

\section{GRÁFICO 1 - Pesquisa: NPS}

\section{Em uma escala de 0 a 10, o quanto você recomendaria a Santa Casa} de Misericórdia de Maceió para um amigo ou colega?

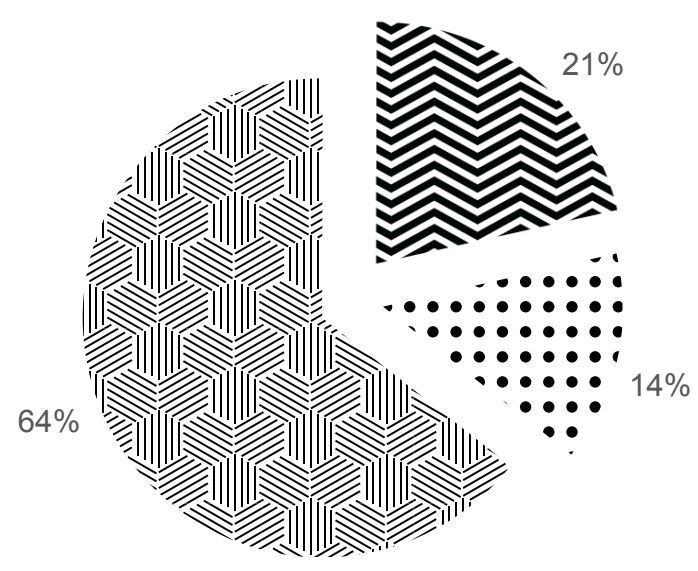

因 Detratores

:: Passivos

Promotores

Nota NPS $=43$

\section{GRÁFICO 2 - Pesquisa: satisfação do cliente}

Como você avalia sua experiência enquanto esteve no local?

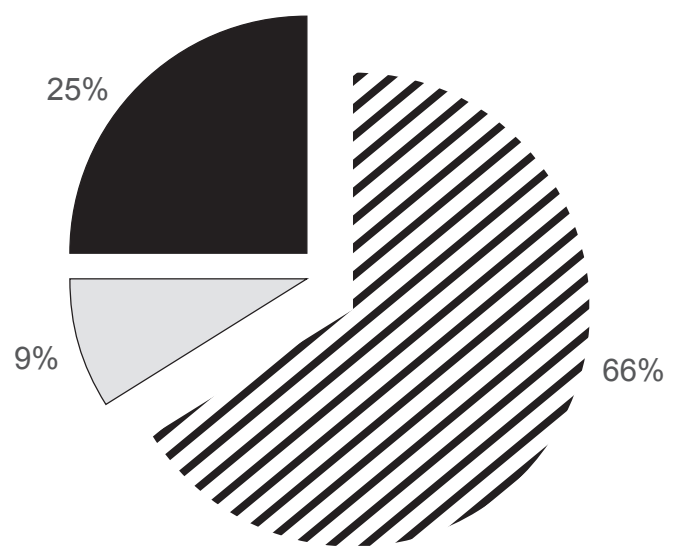


Ao observar os motivos mencionados pelos clientes na Tabela 1, abaixo, podemos concluir que os dois principais motivos que contribuíram na avaliação dos clientes foram: atendimento e tempo de espera.

Ao analisar as reclamações e sugestões dos clientes, relacionadas ao Atendimento e Tempo de espera, pudemos identificar que os gargalos relacionados ao atendimento estão direcionados à cordialidade no atendimento das recepções. Em relação ao tempo de espera, estão direcionados ao tempo de espera para consulta médica. Portanto, como ações de melhorias, a Ouvidoria sugeriu treinamentos direcionados aos colaboradores da recepção, para melhor atender aos clientes. Para minimizar o tempo de espera, sugerimos meios de entretenimento para o cliente, como: internet, revista, TV, enquanto aguarda o atendimento. Também encaminhamos sugestões para as áreas responsáveis de consulta médica, a fim de que promovam melhorias no fluxo dos horários médicos.

\section{TABELA 1 - Pesquisa: principais motivos}

\begin{tabular}{|l|l|}
\hline $\begin{array}{l}\text { Qual o principal motivo que } \\
\text { contribui para sua avaliação? }\end{array}$ & \% \\
\hline ACESSO & 3 \\
\hline AMBIENTE & 2 \\
\hline ATENDIMENTO & 44 \\
\hline COMUNICAÇÃO & 1 \\
\hline CONFIANÇA & 2 \\
\hline HUMANIZAÇÃO & 5 \\
\hline $\begin{array}{l}\text { QUALIFICAÇÃO } \\
\text { PROFISSIONAL }\end{array}$ & 11 \\
\hline QUALIDADE NAASSISTÊNCIA & 4 \\
\hline TEMPO DE ESPERA & 27 \\
\hline
\end{tabular}

Fonte: SOVWEB/2018

\section{CONSIDERAÇÕES FINAIS}

Conclui-se este artigo ressaltando a inclusão do instrumento de pesquisa ao serviço de Ouvidoria como mais um meio de comunicação com o cliente. Foi possível perceber a importância do instrumento de pesquisa para o serviço de Ouvidoria como um aliado para gerenciar o relacionamento com os clientes, além da constatação de que a união da pesquisa com as manifestações dos clientes traz subsídios para traçar melhorias e para a tomada de decisão da instituição.

Embora a pesquisa seja composta apenas por três perguntas, é possível identificar os principais pontos de insatisfação dos clientes e mensurar o quanto eles promovem a Santa Casa de 
Misericórdia de Maceió através de suas recomendações. Os resultados das pesquisas são reflexos das manifestações recebidas na Ouvidoria dos clientes/pacientes da Santa Casa de Misericórdia de Maceió.

Com a pesquisa percebemos que o cliente se sente à vontade para expor sua opinião, sem ter receio de represália. O ideal é que o cliente apresente sua percepção do serviço após a finalização do atendimento, pois terá uma visão de todo o processo (atendimento e assistência). Outro fator importante é passar a contribuição do cliente para os serviços, para com ela as lideranças motivarem os demais de sua equipe, principalmente a linha de frente, a fim de deixar o cliente à vontade para expor suas opiniões.

Os resultados são divulgados para suas áreas específicas, pois com os resultados as lideranças terão suporte para avaliar suas necessidades e assim desenvolver ações para minimizar as insatisfações dos clientes. Além de identificar as causas de insatisfação, é possível identificar quais os pontos em que o hospital vem obtendo o maior índice de satisfação, para poder padronizar essa ação e reforçar essa linha dentro da instituição.

Alcançar a excelência no atendimento é o objetivo de muitas empresas que investem recursos financeiros altos, porém, para atingir a excelência, é necessário ter habilidade e competência em se relacionar. A instituição que visa uma boa qualidade em seus serviços e se importa com a experiência do cliente, busca escutá-lo e promover melhorias necessárias. Quando esses princípios são compreendidos pela instituição, é o momento de pensar em estratégias, tecnologias e processos que darão suporte ao processo operacional.

\section{REFERÊNCIAS}

AUN, Michael. É o cliente que importa. Rio de Janeiro: Sextante, 2012.

BAPTISTA, Renato Dias. A comunicação empresarial na introdução de novas tecnologias. Revista da ESPM, v. 06, 1999.

BELL, J. Projeto de pesquisa. 4. ed. Porto Alegre: Artmed, 2008.

BRASIL. Ministério da Saúde. Secretaria de Gestão Estratégica e Participativa. Departamento de Ouvidoria-Geral do SUS. Manual das Ouvidorias do SUS. Brasília, 2014.

CENTURIÃO, Alberto. Ombudsman: a face da empresa cidadã - como e por que instalar uma Ouvidoria. São Paulo: Educador, 2003.

COSTA, F. J. Mensuração e desenvolvimento de escalas: aplicações em administração. Rio de Janeiro: Ciência Moderna, 2011.

DUARTE, Tomás. Escala Likert: o que é? Disponível em: https://satisfacaodeclientes.com/escala-likert/. Acesso em: 10 jun. 2018.

GUMMESSON, Evert. Marketing de relacionamento total. 3. ed. São Paulo: Bookman, 2010.

KOTLER, Philip. Administração de Marketing: A edição do novo milênio. 10. ed. São Paulo: Prentice Hall, 1998. Marketing Essencial: Conceito, estratégias e casos. 2. ed. São Paulo: Prentice Hall, 2005.

LIKERT, R. A technique for the measurement of attitudes. Archives in Psychology, 140, p. 1-55. 
MINAYO, Maria Cecília de Souza. O desafio do conhecimento: pesquisa qualitativa em saúde. São Paulo/Rio de Janeiro: Abrasco, 1996.

MOTA, João Manoel de Freitas. Comunicação com o cliente. Recife: Livro Rápido, 2008.

ORGANIZAÇÃO NACIONAL DE ACREDITAÇÃO - ONA. Manual Brasileiro de Acreditação - Organizações prestadoras de serviços de saúde. Brasília: ONA, 2016.

PEREIRA, Luiza Helena. A voz do usuário no Sistema Hospitalar: Ouvidorias. Sociologias, 2002, n. 7, p. 82-120.

REICHHELD, Fred. A pergunta definitiva 2.0: Como as empresas que implementam o net promoter score prosperam em um mundo voltado aos clientes. Rio de Janeiro: Elsevier, 2011.

SANTA CASA DE MISERICÓRDIA DE MACEIÓ. História. Disponível em: < http://www.santacasademaceio.com.br/>. Acesso em: 10 jun. 2018.

ZENONE, Luiz Claudio. Fundamentos de marketing de relacionamento: fidelização de clientes e pós-venda. 2. ed. São Paulo: Atlas, 2017. 